\title{
Genomic aberrations in borderline ovarian tumors
}

\author{
Francesca Micci ${ }^{1 *}$, Lisbeth Haugom ${ }^{1}$, Terje Ahlquist ${ }^{2,3}$, Hege K Andersen ${ }^{1}$, Vera M Abeler ${ }^{4}$, Ben Davidson ${ }^{4,6}$, \\ Claes G Trope ${ }^{5}$, Ragnhild A Lothe ${ }^{2,3}$, Sverre Heim ${ }^{1,6}$
}

\begin{abstract}
Background: According to the scientific literature, less than 30 borderline ovarian tumors have been karyotyped and less than 100 analyzed for genomic imbalances by $\mathrm{CGH}$.

Methods: We report a series of borderline ovarian tumors $(n=23)$ analyzed by G-banding and karyotyping as well as high resolution $\mathrm{CGH}$; in addition, the tumors were analyzed for microsatellite stability status and by FISH for possible $6 \mathrm{q}$ deletion.

Results: All informative tumors were microsatellite stable and none had a deletion in $6 \mathrm{q} 27$. All cases with an abnormal karyotype had simple chromosomal aberrations with +7 and +12 as the most common. In three tumors with single structural rearrangements, a common breakpoint in $3 q 13$ was detected. The major copy number changes detected in the borderline tumors were gains from chromosome arms $2 q, 6 q, 8 q, 9 p$, and $13 q$ and losses from 1p, 12q, 14q, 15q, 16p, 17p, 17q, 19p, 19q, and 22q. The series included five pairs of bilateral tumors and, in two of these pairs, informative data were obtained as to their clonal relationship. In both pairs, similarities were found between the tumors from the right and left side, strongly indicating that bilaterality had occurred via a metastatic process. The bilateral tumors as a group showed more aberrations than did the unilateral ones, consistent with the view that bilaterality is a sign of more advanced disease.
\end{abstract}

Conclusion: Because some of the imbalances found in borderline ovarian tumors seem to be similar to imbalances already known from the more extensively studied overt ovarian carcinomas, we speculate that the subset of borderline tumors with detectable imbalances or karyotypic aberrations may contain a smaller subset of tumors with a tendency to develop a more malignant phenotype. The group of borderline tumors with no imbalances would, in this line of thinking, have less or no propensity for clonal evolution and development to full-blown carcinomas.

\section{Introduction}

Borderline ovarian tumors are of low malignant potential. They exhibit more atypical epithelial proliferation than is seen in adenomas, their benign counterpart, but are without the destructive stromal invasion characteristic of overt adenocarcinomas [1]. Although the clinical and pathological features of tumors of borderline malignancy thus are intermediate, it is not clear whether they represent a transitional form between adenomas and invasive carcinomas, as a stage in multistep carcinogenesis, or alternatively, whether all three tumor types

\footnotetext{
* Correspondence: francesca.micci@labmed.uio.no

'Section for Cancer Cytogenetics, Institute for Medical Informatics, The Norwegian Radium Hospital, Oslo University Hospital, Oslo, Norway
}

should be regarded as independent entities brought about by different molecular mechanisms [1,2].

Although a comparison of the cytogenetic abnormalities occurring in ovarian carcinomas and tumors of borderline malignancy could provide insights into their pathogenetic relationship, little information is available on the karyotypic patterns of the latter tumors. Indeed, whereas chromosomal abnormalities have been reported in over 400 ovarian carcinomas [3], the corresponding cytogenetic information on borderline tumors is limited to only 27 cases [4-11]. Karyotypic simplicity with few or no structural rearrangements seems to be characteristic with trisomies for chromosomes 7 and 12 as the most common abnormalities [6-9]. Using fluorescent in situ hybridization (FISH), Tibiletti et al. [2] found 
consistent loss of a small area of 6q in a high percentage of borderline ovarian tumors.

Several studies have used comparative genomic hybridization $(\mathrm{CGH})$ to identify the imbalances present in tumor genomes, also in the ovarian context. Of nearly 100 borderline tumors analyzed, half have shown genomic imbalances. The most frequent abnormalities thus detected have been gains of or from chromosomes 5, 8, and 12 and losses from $1 \mathrm{p}$ [12-17].

We here report a series $(n=23)$ of borderline ovarian tumors analyzed by G-banding, high resolution (HR)$\mathrm{CGH}$, FISH-examination for possible $6 \mathrm{q}$ deletions and 3q rearrangements, and a microsatellite instability (MSI) assay. The latter analysis was included because ovarian cancer can be part of the hereditary non-polyposis colon cancer (HNPCC) spectrum which is often characterized by MSI.

\section{Materials and methods}

Tumors

The examined material consisted of 23 fresh samples from ovarian tumors surgically removed at The Norwegian Radium Hospital from 2001 to 2004 (Table 1). The tumors were all classified as borderline, either with serous (17 cases, Fig. 1), mucinous (5 cases), or a mixed serous and mucinous differentiation (case 18). In five patients, bilateral borderline tumors were analyzed (cases 7 and 8, 9 and 10,13 and 14, 19 and 20, and 22 and 23; hence, the total number of patients was 18). The utilization of the tumor material for research purposes was approved by institutional as well as regional ethical committees.

\section{Cell Culturing and Karyotyping}

The tumor samples were manually minced and disaggregated with Collagen II (Worthington, Freehold, NJ, USA) until a suitable suspension of cells and cell clumps was obtained. After 6-7 days of culturing in a selective medium [18], colchicine was added and the cultures harvested according to Mandahl [19]. The chromosomes of the dividing cells were then G-banded and a karyotype established according to the recommendations of the ISCN [20].

\section{Fluorescence in Situ Hybridization (FISH) Analyses}

BAC clones retrieved from the RPCI-11 Human BAC library and the CalTech human BAC library (P. de Jong libraries, http://bacpac.chori.org/home.htm) were used. The clones were selected according to their physical and genetic mapping data on chromosomes 3 and 6 as reported by the Human Genome Browser at the University of California, Santa Cruz website http://genome. ucsc.edu/. The clones specific for chromosome 3 were selected because they mapped to around the $3 \mathrm{q} 13$ breakpoint seen in three of the tumors we examined (see below and Table 2). The clones mapping on chromosome 6 spanned the region between markers D6S193 and D6S149, i.e., the consistent deletion reported by Tibiletti et al. [2] in the chromosomal region 167, 113, 548-167, 765, 926 in band 6q27 (Table 2). All clones were grown in selective media and DNA was extracted according to standard methods [21], DNA probes were directly labelled with a combination of fluorescein isothiocyanate (FITC)-12-deoxicytidine triphosphate (dCTP) and FITC-12-2-deoxyuridine triphosphate (dUTP), Texas Red-6-dCTP and Texas Red-dUTP (New England Nuclear, Boston, MA, USA), and Cy3-dCTP (GE Healthcare, UK) by nick translation. The subsequent hybridization conditions as well as the detection procedure were according to standard protocols [22]. The hybridizations were analyzed using a CytoVision system (Applied Imaging, Newcastle, UK).

\section{High-Resolution Comparative Genomic Hybridization (HR- (GH)}

DNA was isolated by the phenol-chloroform method as previously described [23]. CGH was performed according to our modifications of standard procedures $[24,25]$. Chromosomes were karyotyped based on their inverted DAPI appearance and the relative hybridization signal intensity was determined along each chromosome. On average, 10-15 metaphases were analyzed. A negative (normal versus normal; the normal control was a pool of DNAs from four healthy women) and a positive (the colon cancer cell line LOVO with known copy number changes) control were included in the experiments. For the scoring of CGH results, we adopted the use of dynamic standard reference intervals (D-SRI). A D-SRI represents a "normal" ratio profile that takes into account the amount of variation detected in negative controls for each chromosome band. This provides a more objective and sensitive scoring criterion than fixed thresholds [26-28] and, consequently, a higher resolution. The D-SRI used was generated with data from 10 normal versus normal hybridizations (totalling 110 cells). This interval was automatically scaled onto each sample profile, and aberrations were scored whenever the case profile and the standard reference profile at $99 \%$ confidence intervals did not overlap. The description of the CGH copy number changes was based on the recommendation of the ISCN [20].

\section{Microsatellite Instability Status}

Microsatellite instability (MSI) status was determined in all samples using a consensus panel of five microsatellite markers (BAT25, BAT26, D2S123, D5S346, and D17S250) [29]. A tumor was considered to be MSI-high 
Table 1 Borderline Ovarian Tumors Examined by Karyotyping, High Resolution-CGH, and Microsatellite Instability Analysis.

\begin{tabular}{|c|c|c|c|c|c|c|}
\hline $\begin{array}{l}\text { Case num/ } \\
\text { lab num }\end{array}$ & Type & Surface & Extraovarian & Karyotype & Genomic imbalances & $\begin{array}{l}\text { MS } \\
\text { status }\end{array}$ \\
\hline $1 / 01-642$ & mucinous & no & no & $\begin{array}{l}47, X X,+12[4] / 47, X X,+7 \\
{[3] / 45, X X,-6[3] / 46, X X[63]}\end{array}$ & $\begin{array}{l}\text { rev ish enh(1q22q32, 2p25, 2q22q24, 2q32q33, 3p12p14, } \\
3 p 22,3 p 23,3 p 24,3 q 12 q 13,3 q 24,3 q 25,5 p 14,5 q 14 q 22, \\
6 q 12 q 21,6 q 22 q 23,8 q 13,8 q 21,8 q 22 q 24,9 p 13 p 21,9 p 23, \\
10 q 21,18 q 12), \operatorname{dim}(1 p 21,1 p 31 p t e r, 7 q 11,11 p 15, \\
11 q 12 q 14,11 q 23,12 q 23,12 q 24,13 q 12,13 q 14,13 q 33 q 34, \\
14 q 21 q 24,14 q 31 q 32,15 q 13 q 14,15 q 22 q 24,17 p 11 p 13, \\
17 q, 19 p 13,19 q, 22 q 11 q 13)\end{array}$ & MSS \\
\hline $2 / 01-700$ & mucinous & no & no & $46, X X[116]$ & $\begin{array}{l}\text { rev ish enh(8q23,9p23), } \operatorname{dim}(1 p 34 p 35,7 q 11,17 p 12 p 13 \\
19 p 13,19 q 13,22 q 11 q 12)\end{array}$ & MSS \\
\hline $3 / 01-839$ & serous & yes & $\begin{array}{l}\text { non-invasive } \\
\text { implants }\end{array}$ & $\begin{array}{l}46, X X, t(3 ; 17)(q 13 ; q 24)[2] / \\
46, X X[45]\end{array}$ & $\begin{array}{l}\text { rev ish enh(3p13, 9p23p24), dim(1p33pter, 7q11, 9q34, } \\
11 q 13,12 q 24,16 p 11 p 13,17 p 12 p t e r, 17 q 12 q 21,19 p 13 \\
19 q, 22 q 11 q 13)\end{array}$ & $\begin{array}{l}\text { no DNA } \\
\text { available }\end{array}$ \\
\hline $4 / 01-844$ & mucinous & no & no & $\begin{array}{l}46, X X,+12,-22[7] / 46, X X \\
{[19]}\end{array}$ & no DNA available & MSS \\
\hline $5 / 02-1$ & serous & yes & no & $46, X X[16] / 92, X X X X[23]$ & $\begin{array}{l}\text { rev ish enh(2q22q24, 2q31q32, 3p12, 3q12q13, 4p15, } \\
4 q 13,5 p 14,5 q 14 q 23,6 q 15 q 16,8 q 22,8 q 23,13 q 21 q 31 \\
13 q 32,21 q 21), \operatorname{dim}(1 p 32 p t e r, 2 q 37,3 p 21,4 q 35,5 q 35 \\
6 p 21,6 p 22,6 q 25,7 q 11,9 q 22,9 q 33 q t e r, 10 q 26 \\
11 q 12 q 13,12 p 11 p 12,12 p 13,12 q 23 q 24,14 q 31 \\
15 q 22 q 24,16 p 11 p 13,16 q 22 q 23,17 p 11 p 13,17 q 11 q 21 \\
17 q 22 q 24,19 p 13,19 q 13,20 q 11 q 13,21 q 22,22 q 11 q 13)\end{array}$ & MSS \\
\hline $6 / 02-329$ & serous & yes & $\begin{array}{l}\text { invasive } \\
\text { implants }\end{array}$ & $46, X X[28]$ & no imbalances & $\begin{array}{l}\text { no DNA } \\
\text { available }\end{array}$ \\
\hline 7/02-828 A & $\begin{array}{l}\text { Serous } \\
\text { (right } \\
\text { ovary) }\end{array}$ & yes & no & $46, X X[13] / 92, X X X X[7]$ & $\begin{array}{l}\text { rev ish enh(4p15, 8q22q23, 13q22q31, 13q32), dim } \\
(1 p 32 p 36,7 p 12 p 13,7 q 11,9 q 34,11 q 12 q 13,12 p 11 p 12 \\
12 q 23,12 q 24,15 q 22 q 24,16 p 13,17 p 12 \text { pter, 17q11q21, } \\
\text { 19, 22q11q13) }\end{array}$ & MSS \\
\hline $8 / 02-829$ B & $\begin{array}{l}\text { serous } \\
\text { (left ovary) }\end{array}$ & yes & no & 46, XX[106]/92, XXXX[9] & no DNA available & - \\
\hline $9 / 03-325 \mathrm{~A}$ & $\begin{array}{l}\text { serous } \\
\text { (right } \\
\text { ovary) }\end{array}$ & yes & no & $46, X X[15]$ & $\begin{array}{l}\text { rev ish enh(3p12p14, 3q13, 5p14, 6q15q16, 8q22q23, } \\
\text { 9p21, 18q12), dim(1p31pter, 2q37, 7q11, 11q12q13, } \\
12 q 24,16 p 11 p 13,17 p 11 p 13,17 q 11 q 21,17 q 23 q 25,19 p \\
19 q 13,22 q 11 q 13)\end{array}$ & MSS \\
\hline 10/03-328 B & $\begin{array}{l}\text { serous } \\
\text { (left ovary) }\end{array}$ & yes & no & $46, X X[15]$ & no imbalances & MSS \\
\hline $11 / 03-401$ & serous & no & no & Culture failure & $\begin{array}{l}\text { rev ish enh(1p32pter, 1q21q22, 2p11p12, 2q37, 3p21, } \\
4 p 16,6 p 12 p 21,9 q 33 q t e r, 10 q 22 q 23,10 q 24,10 q 25 \\
10 q 26,11 q 11 q 14,12 q 24,14 q 32,15 q 22 q 25,16 p \\
16 q 13 q t e r, 17 p, 17 q 11 q 22,17 q 24 q t e r, 19 p 13,19 q 13 \\
20 p 11 p 12,20 q 13,22 q 11 q 13), \operatorname{dim}(6 q 15 q 21,6 q 22 q 24)\end{array}$ & MSS \\
\hline $12 / 03-481$ & serous & yes & no & $46, \times X[32]$ & no imbalances & MSS \\
\hline $13 / 03-620 \mathrm{~A}$ & $\begin{array}{l}\text { serous } \\
\text { (right } \\
\text { ovary) }\end{array}$ & yes & $\begin{array}{l}\text { metastasis } \\
\text { lympho } \\
\text { node }\end{array}$ & $\begin{array}{l}46, X X, \operatorname{der}(4) t(3 ; 4)(q 13 ; \\
q 34)[15] / 46, X X[2]\end{array}$ & no imbalances & MSS \\
\hline $14 / 03-621$ B & $\begin{array}{l}\text { serous } \\
\text { (left ovary) }\end{array}$ & yes & $\begin{array}{l}\text { metastasis } \\
\text { lympho } \\
\text { node }\end{array}$ & $\begin{array}{l}46, X X, \operatorname{der}(4) t(3 ; 4)(q 13 ; \\
q 34)[10] / 46, X X[5]\end{array}$ & no imbalances & MSS \\
\hline $15 / 03-701$ & serous & no & no & $46, X X[11]$ & no imbalances & MSS \\
\hline $16 / 04-36$ & serous & yes & $\begin{array}{l}\text { invasive } \\
\text { implants }\end{array}$ & $\begin{array}{l}49, X X,+3,+7, i(8)(q 10) \\
+12[15] / 50, \text { idem, }+r[2] / \\
50, \text { idem, }-r,+\operatorname{mar}[2]\end{array}$ & rev ish enh(3, 7, 8q13qter, 12), dim(8p22pter) & MSS \\
\hline $17 / 04-682$ & mucinous & no & no & $46, X X[3]$ & no DNA available & - \\
\hline $18 / 04-721$ & $\begin{array}{l}\text { mucinous } \\
\text { and } \\
\text { serous }\end{array}$ & no & no & $46, X X[18]$ & no imbalances & MSS \\
\hline
\end{tabular}


Table 1: Borderline Ovarian Tumors Examined by Karyotyping, High Resolution-CGH, and Microsatellite Instability Analysis. (Continued)

\begin{tabular}{|c|c|c|c|c|c|c|}
\hline 19/04-831 A & $\begin{array}{l}\text { serous } \\
\text { (left ovary) }\end{array}$ & yes & $\begin{array}{l}\text { invasive } \\
\text { implants }\end{array}$ & $46, X X[84]$ & $\begin{array}{l}\text { rev ish enh(2q24,3p12,3p13, 8q22q23, 13q22q31), dim } \\
(2 q 36 q 37,7 q 35 q 36,9 q 33 q 34,10 q 25 q 26,11 q 13 \\
12 q 23 q 24,14 q 31 q 32,15 q 22 q 24,16 p 11 p 13,17 p 11 p 13 \\
17 q 11 q 21,17 q 22 q 25,19 p 13,19 q 13,20 q 11 q 13,22 q)\end{array}$ & MSS \\
\hline 20/04-832 B & $\begin{array}{l}\text { serous } \\
\text { (right } \\
\text { ovary) }\end{array}$ & yes & $\begin{array}{l}\text { invasive } \\
\text { implants }\end{array}$ & $47, X X,+7[18]$ & $\begin{array}{l}\text { rev ish enh(Xq21q23, 2q22q32, 3p12p13, 3q12q13, } \\
4 q 12 q 28,5 p 13 p 14,5 q 14 q 23,6 q 12 q 21,6 q 22,7 p 12 p 21, \\
7 q 21 q 34,8 q 13 q 21,8 q 22 q 23,9 p 21 p 24,11 q 14 q 21, \\
13 q 21 q 31), \operatorname{dim}(1 p 32 p t e r, 2 q 37,4 p 16,6 p 23,6 q 25 q 26, \\
9 q 34,10 q 25 q 26,11 q 12 q 13,12 q 23 q 24,14 q 31 q 32, \\
15 q 22 q 24,16 p 11 p 13,16 q 21 q 24,17 p, 17 q 11 q 21, \\
17 q 23 q 24,19,20 q 11 q 13,21 q 22,22 q)\end{array}$ & MSS \\
\hline 21/04-1211 & mucinous & no & no & Culture failure & no imbalances & MSS \\
\hline 22/04-1213 A & $\begin{array}{l}\text { serous } \\
\text { (right } \\
\text { ovary) }\end{array}$ & yes & $\begin{array}{l}\text { invasive } \\
\text { implants }\end{array}$ & $46, X X[3]$ & $\begin{array}{l}\text { rev ish enh(8p11p23, 8q11q24), dim(1p34p35, 15q11q13, } \\
16 p 11 p 12)\end{array}$ & MSS \\
\hline 23/04-1214 B & $\begin{array}{l}\text { serous } \\
\text { (left ovary) }\end{array}$ & yes & $\begin{array}{l}\text { invasive } \\
\text { implants }\end{array}$ & $46, X X[3]$ & no DNA available & - \\
\hline
\end{tabular}

if two or more of the five markers exhibited novel alleles compared to normal DNA, MSI-low if only one marker deviated from the normal pattern, and microsatellite stable (MSS) if none of the tumor genotypes showed an aberrant pattern. Control DNA corresponding to the individual tumors was not available from the patients and therefore single allele changes, i.e., the presence of two different alleles, can reflect a heterozygous constitutional genotype or a homozygous genotype with a novel tumor-specific allele. Thus, dinucleotide markers were not scored when such a pattern appeared in the tumors. The MSI status was assessed according to $\mathrm{Wu}$ et al. [30]. Allelic sizes were determined using GeneMapper 3.7 software (Applied Biosystems, Foster City, CA, USA) and the results were independently scored by two investigators. A second round of analyses was always performed and confirmed the findings.

\section{Results}

The cell culturing and subsequent G-banding cytogenetic analysis gave informative results in 21 samples (Table 1), seven of which showed an abnormal karyotype whereas 14 were normal. The remaining two samples were culture failures and therefore could not be examined using this technique. All the cases with an abnormal karyotype had simple chromosomal aberrations. In three tumors, a single structural rearrangement was seen in a pseudodiploid karyotype: a $\mathrm{t}(3 ; 17)$ (q13; $\mathrm{q} 24)$ was detected in case 3 and $a \operatorname{der}(4) \mathrm{t}(3 ; 4)(\mathrm{q} 13 ; \mathrm{q} 34)$ was seen in cases 13 and 14, which were bilateral tumors from the same woman. In case 1, three unrelated clones with a single numerical aberration in each were identified. In case 16 , three related clones were seen: $49, \mathrm{XX},+3,+7, \mathrm{i}(8)(\mathrm{q} 10),+12[15] / 50$, idem, $+\mathrm{r}[2] /$ 50 , idem, $-r,+\operatorname{mar}[2]$. Numerical changes only were
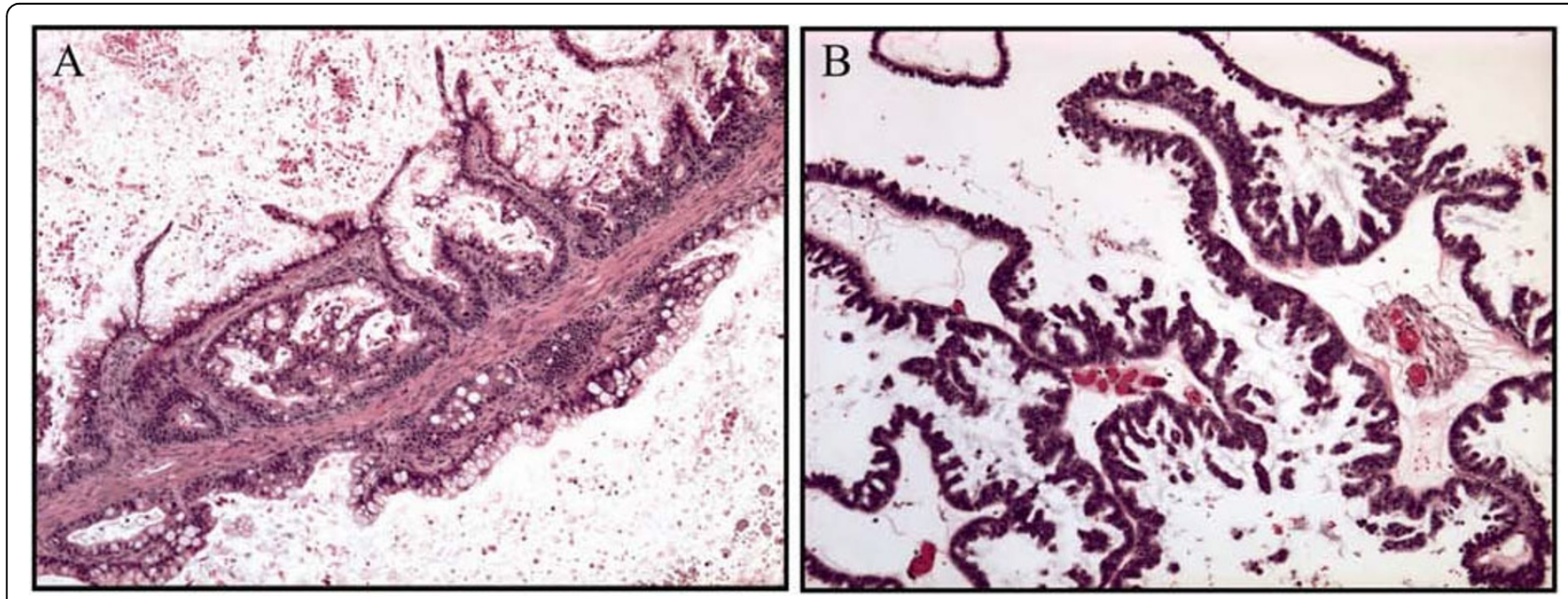

Figure 1 Histological sections from case 17 (a) a mucinous and case 7 (b), a serous borderline ovarian tumor. 
Table 2 Clones Used for FISH Experiments.

\begin{tabular}{lll}
\hline BAC clone & Map position & UCSC position (hg18) \\
\hline RP11-631J1 & $3 q 12.2$ & chr3:101, 560, 061-101, 723, 941 \\
\hline CTD-2303M9 & $3 q 13.2$ & chr3:113, 489, 978-113, 592, 063 \\
\hline RP11-514O12 & $6 q 27$ & chr6:167, 113, 548-167, 270, 484 \\
\hline CTD-2383F8 & $6 q 27$ & chr6:167, 253, 486-167, 374, 339 \\
\hline CTD-3184N3 & $6 q 27$ & chr6:167, 404, 540-167, 588, 046 \\
\hline RP11-931J21 & $6 q 27$ & chr6:167, 592, 153-167, 765, 915 \\
\hline RP11-178P20 & $6 q 27$ & chr6:167, 616, 370-167, 765, 926 \\
\hline
\end{tabular}

found in three cases. Chromosomes 7 and 12 were most often involved in numerical changes (in three cases each, always as trisomies), whereas chromosomal band $3 \mathrm{q} 13$ was involved in the three cases showing only a structural rearrangement.

The HR-CGH gave informative results in 19 samples showing genomic imbalances in 11 of them (Table 1). From four lesions there was no DNA available for analysis. In six cases, the G-banding karyotype matched the pattern detected by CGH; five of them had a normal karyotype and showed no imbalances by HR-CGH whereas the last tumor (case 16) had numerical and structural changes all detected by both techniques. In six tumors, HR-CGH detected imbalances where Gbanding analysis showed only normal karyotypes.
The tumors showed from five (samples 16 and 22) to 41 (sample 1) imbalances by HR-CGH with an average number of copy alterations (ANCA) index of 18.72. No amplifications were scored. The major copy number changes detected in the borderline tumors were gains from chromosome arms $2 \mathrm{q}, 6 \mathrm{q}, 8 \mathrm{q}, 9 \mathrm{p}$, and $13 \mathrm{q}$ and losses from 1p, 12q, 14q, 15q, 16p, 17p, 17q, 19p, 19q, and 22q (Fig. 2). More specifically, the most frequently gained bands were, in order of decreasing frequency, $8 \mathrm{q} 23$ (82\% of the cases showing imbalances), and 2q24, 6q15 16, 8q13 21, 9p23, and 13q22 31 (36\%). The most frequently lost bands were 1p34 35, 17p12 13, 19p13, 19q13, and 22q11 12 (73\%), 17q12 21 (64\%), 16p11 13 (55\%), 15q22 24, and 17q23 24 (45\%), and $12 \mathrm{q} 23 \sim 24$ and $14 \mathrm{q} 31$ (36\%).

The HR-CGH analysis gave informative results from both tumorous ovaries in two patients with bilateral disease (cases 13 and 14 and 19 and 20). The common imbalances found in these samples were gains of 2q24, 8q22 23, and 13q22 31 and losses of 9q34, 10q25 26, 12q23 24, 14q31 32, 15q22 24, 16p, 17p, 17q11 21, 17q23 24, 20q and 22q.

FISH was performed for two purposes: to characterize, possibly identify, the common breakpoint in 3q13 (seen in cases 3,13 , and 14; the latter two were from bilateral tumors in the same woman) and to test for the consistent deletion previously found in borderline ovarian

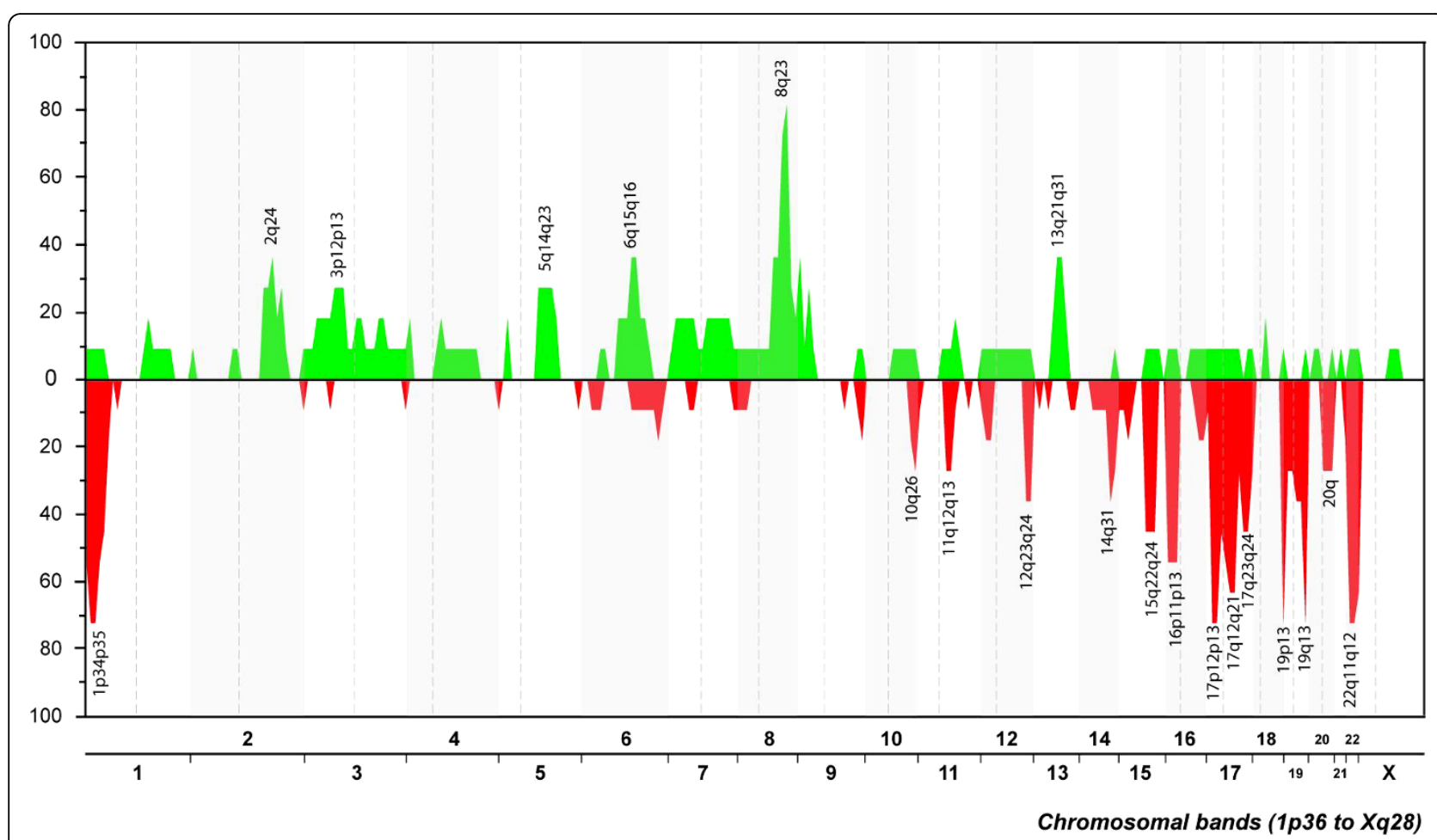

Figure 2 The genomic imbalances detected by HR-CGH in 11 borderline ovarian tumors. Gains are shown in green and losses in red color. 
tumors by Tibiletti et al. [2]. For the former purpose, FISH was performed on cases 13 and 14 on previously hybridized (stripped) slides; however, we did not get informative results. To examine for $6 \mathrm{q}$ deletions, FISH was performed on a total of 12 tumors. In nine cases, newly dropped slides were made, whereas in three cases old slides previously used for other FISH experiments were stripped and used. Because no metaphase spreads were available for FISH analysis, interphase nuclei were used to check for the reported deletion on 6q. A total of 200 nuclei per sample were analyzed but no indication of a deletion of the alleged $6 \mathrm{q}$ target region was detected in the nine cases yielding informative results.

The testing for MSI gave informative results in 18 tumors. All of them were classified as microsatellite stable (MSS) as none of the tumor genotypes showed an aberrant pattern. The remaining five samples were not analyzed because there was no DNA available.

\section{Discussion}

FISH experiments were performed to investigate whether the about $300 \mathrm{~kb}$ deletion in $6 \mathrm{q} 27$ found so consistently by Tibiletti et al. [2] in borderline ovarian tumors was a feature also of the tumors of our series. In none of nine informative cases (five with a normal karyotype, four with clonal chromosome abnormalities) did we see any such deletion. We cannot offer any biological explanation for the discrepant results, and so future studies will be necessary to find out what is more typical of borderline tumors.

MS status has previously been analyzed in a total of 112 ovarian tumors of borderline malignancy, 14 of which showed instability for one or more of the markers used. However, some studies were performed before the consensus reached by NCI for evaluating MSI [29] and therefore differences in the type and number of microsatellites can be found in these studies [31-36]. All 18 informative borderline ovarian tumors examined by us turned out to be microsatellite stable (MSS). Based on the results of our and the latest other studies [34-36], it therefore seems that at least the great majority of ovarian tumors of borderline malignancy tend to have a stable MS pattern.

The pattern of chromosomal aberrations seen by Gbanding analysis in the present study with gains of chromosomes 7 and 12 as recurrent changes is largely similar to that previously found in abnormal karyotypes of ovarian borderline tumors and well differentiated carcinomas $[8,9]$. Poorly differentiated and/or advanced stage ovarian carcinomas, on the other hand, tend to have more complex karyotypes with multiple numerical as well as structural aberrations $[18,37]$. A novel finding, however, was that three tumors (cases 3,13 , and 14; admittedly, the last two were from the same patient) showed a single structural aberration that seemed to involve chromosomal band 3q13. Unfortunately, we did not have left fixed cells in suspension to perform FISH experiments on newly dropped slides, and our attempts to use stripped slides for better FISH characterization failed. Nevertheless, the detected G-banding similarity hints that one or more genes mapping to this band may play a pathogenetic role in a subset of borderline ovarian tumors.

Most tumor karyotypes in the present series were normal, as only seven of 21 successfully cultured samples showed clonal chromosome abnormalities. The simplest explanation for this is that the cells carrying aberrations did not divide in vitro and therefore could not be detected by G-banding analysis. Confirmation that this was indeed so stems from the observation that six tumors with a normal karyotype showed genomic imbalances by HR-CGH. However, in the five tumors where both G-banding and HR-CGH analyses gave a normal karyotype and no imbalances, one must assume that either no aberrations were present in at least a substantial minority of the cells or they were too small to be seen at the chromosomal resolution level.

The major copy number changes detected in the borderline tumors were gains of chromosomal bands or regions $8 \mathrm{q} 23$ (present in $82 \%$ of the cases showing imbalances), 2q24, 6q15 16, 8q13 21, 9p23, and 13q22 31 (36\%), and losses of $1 \mathrm{p} 34 \sim 35,17 \mathrm{p} 12 \sim 13$, 19p13, 19q13, 22q11 12 (73\%), 17q12 21 (64\%), 16p11 13 (55\%), 15q22 24, and 17q23 q24 (45\%), and 12q23 24 and 14q31 (36\%). Some of these imbalances have already been reported by other groups such as gain of $8 \mathrm{q}$ and losses of $1 \mathrm{p}$ and chromosome 17 [12,14-16,38]. However, the use of HR-CGH allowed us to increase the resolution and narrow down the mentioned regions to $8 \mathrm{q} 23,1 \mathrm{p} 34 \sim 35,17 \mathrm{p} 12 \sim 13,17 \mathrm{q} 12 \sim 21$, and $17 \mathrm{q} 23 \sim 24$. Additional studies are needed to better investigate the nature of the gene(s) present here that may be involved in the genesis or progression of ovarian borderline tumors.

Much interest has focused on the loss of genetic information from chromosome 17 in ovarian tumors. In the short arm, losses seem to occur especially at $17 \mathrm{p} 13.3$ [39-41] with OVCA1 and OVCA2 as possible target tumor suppressor genes [42]. However, proximal $17 \mathrm{p}$ changes have received more attention. Mutation of the gene TP53 in $17 \mathrm{p} 13.1$ is the most common genetic alteration thus far detected in ovarian cancer, with mutation rates as high as $50 \%$ in advanced stage carcinomas [43]. The frequency of TP53 alterations varies depending on whether the tumors are benign, borderline, or malignant as well as on the histological subtype, i.e., serous, mucinous, endometrioid, and clear cell ovarian carcinoma. In benign epithelial ovarian tumors no 
mutation of TP53 has been described [44,45]. In borderline tumors, TP53 mutation and over-expression may occur, but are not common [46-48]. In malignant tumors, the prevalence of TP53 gene mutations increases with increasing stage [44]. In the long arm of chromosome 17 , losses at $17 \mathrm{q} 12 \sim 21$ are frequently observed in ovarian carcinomas [39,49], but this is the first time that chromosomal regions $17 \mathrm{q} 12 \sim 21$ and $17 q 23 \sim 24$ are identified as lost in ovarian borderline tumors. The breast and ovarian cancer susceptibility gene $B R C A 1$ maps to $17 \mathrm{q} 21$ and could be one possible gene target, but the actual pathogenetic involvement of this and other genes located in 17q needs to be further investigated.

The present series of borderline ovarian tumors is the largest one hitherto analyzed for genomic imbalances and the first examined by HR-CGH. In addition to the above-mentioned imbalances, we also identified some new chromosomal regions gained at a high frequencies, i.e., $2 \mathrm{q} 24,6 \mathrm{q} 15 \sim 16,8 \mathrm{q} 13 \sim 21,9 \mathrm{p} 23$, and 13q22 31 (36\%), as well as losses of 19p13,19q13, and 22q11 12 (73\%), 16p11 13 (55\%), 15q22 24 (45\%), and 12q23 24 and $14 \mathrm{q} 31$ (36\%). Again, further studies are needed to investigate the possible involvement of genes present here in ovarian tumorigenesis. The aberrations found in the two histological subtypes of borderline tumors (serous versus mucinous) were also compared but no specific difference was noted.

The present series included five patients with bilateral borderline tumors. Informative results were obtained by HR-CGH from both tumorous ovaries in two patients (pairs 13 and 14 and 19 and 20). Cases 13 and 14 showed the same unbalanced 3;4-translocation by karyotyping in both tumorous ovaries. This is a sure sign that the bilateral tumors were part of a single neoplastic process and, hence, that one of them must have occurred by a metastatic mechanism. No imbalances were seen by HR-CGH in this tumor pair, probably because too little was contributed by cells of the neoplastic parenchyma to the total DNA extracted. In cases 19 and 20, a +7 was seen in one tumor whereas the other showed a normal karyotype; this technique therefore did not yield certain information as to the two tumors' clonal relationship. However, common imbalances were found by HR-CGH such as gains of 2q24, 8q22 23, and 13q22 31 and losses of 9q34, 10q25 26, 12q23 24, 14q31 32, 15q22 24, 16p, 17p, 17q11 21, 17q23 24, 20q and 22q. The data are too small for anything but speculations, but it is possible that these bands/regions may carry gene(s) important for the development of bilateral borderline ovarian tumors. It is in this context intriguing that the same imbalances also occurred in some of the other bilateral tumors, albeit then found in only one tumorous ovary while the other was uninformative. But regardless of what, if any, pathogenetic changes might contribute to the development of bilateral borderline tumors particularly, the combined karyotypic/CGH data on the two only completely informative pairs strongly indicate that bilaterality occurs by spreading from one side to the other, not as two clonally separate processes.

The average number of copy alterations per tumor calculated in the present series was 18.72. It is interesting to note that for the bilateral borderline ovarian tumors the ANCA index was 24.5 whereas for the unilateral borderline ovarian tumors it was 17.44. This difference, small though it may seem, is consistent with the interpretation that bilateral tumors reflect a more advanced disease stage compared with unilateral ones, inasmuch as they arise via the spreading process referred to above.

\section{Conclusion}

The introductory question as to whether borderline tumors of the ovary represent a transitional stage from benign to clearly malignant or a pathogenetically "closed" tumor type of its own, without a tendency to further progression, remains, perhaps not surprisingly, unanswered by the findings of the present study. It may be worthy of note, however, that two main genomic groups of tumors were discerned in this series, one $(\mathrm{n}=$ 5) showing a normal karyotype and no imbalances detectable by HR-CGH and the other $(\mathrm{n}=14)$ showing aberrations by one or both analytical methods. Possibly, and we underscore that this is presently only a speculation, tumors of the first group are more developmentally stable and may have no propensity to progress to more malignant carcinomas, whereas those of the second group with chromosomal/genomic aberrations may undergo further evolutionary changes giving rise to a more malignant phenotype. The fact that gain of chromosomal band 8q23, as well as losses of $19 \mathrm{p} 13$ and $19 \mathrm{q} 13$, feature prominently in both overt carcinomas $[37,50]$ and in the present series (the gains were found in 5 of 5 cases with bilateral borderline tumors and in 4 of 6 informative unilateral tumors showing imbalances) fits, but by no means proves, this hypothesis. To further validate it would require more extensive studies that should not only compare the karyotypic/genomic findings of borderline and malignant tumors, but should also collate these findings with clinical information on the same group of patients.

\section{Acknowledgements}

This work was supported by grants from the Norwegian Cancer Society and Helse Sør-Øst. 


\begin{abstract}
Author details
${ }^{1}$ Section for Cancer Cytogenetics, Institute for Medical Informatics, The Norwegian Radium Hospital, Oslo University Hospital, Oslo, Norway. ${ }^{2}$ Department of Cancer Prevention, Institute for Cancer Research, The Norwegian Radium Hospital, Oslo University Hospital, Oslo, Norway. ${ }^{3}$ Centre for Cancer Biomedicine, University of Oslo, Oslo, Norway. ${ }^{4}$ Department of Pathology, The Norwegian Radium Hospital, Oslo University Hospital, Oslo, Norway. ${ }^{5}$ Department of Gynecology, The Norwegian Radium Hospital, Oslo University Hospital, Oslo, Norway. ${ }^{6}$ Faculty of Medicine, University of Oslo, Oslo, Norway.
\end{abstract}

\section{Authors' contributions}

FM conducted the study, participated in design, coordination, data interpretation, and drafted the manuscript. LH participated in karyotyping and FISH experiments. TA and RAL participated in MS status analysis and discussion of data. HKA participated in FISH analysis. VMA and BD performed the pathological diagnosis of each tumor and provided samples for cytogenetic analysis. CGT provided samples and clinical information. SH participated in the design and coordination of the study and critically revised the manuscript. All authors read and approved the final manuscript.

\section{Competing interests}

The authors declare that they have no competing interests.

Received: 1 December 2009

Accepted: 26 February 2010 Published: 26 February 2010

\section{References}

1. Tavassoli FA, Devilee P: Tumors of the breast and female genital organs World Health Organization Classification of Tumors Lyon: IARC Press 2003.

2. Tibiletti MG, Bernasconi B, Furlan D, Bressan P, Cerutti R, Facco C, Franchi M, Riva C, Cinquetti R, Capella C, Taramelli R: Chromosome 6 abnormalities in ovarian surface epithelial tumors of borderline malignancy suggest a genetic continuum in the progression model of ovarian neoplasms. Clin Cancer Res 2001, 7:3404-3409.

3. Mitelman database of chromosome aberrations in cancer. http://cgap.nci. nih.gov/Chromosomes/Mitelman.

4. Knoerr-Gaertner H, Schuhmann R, Kraus H, Uebele-Kallhardt B: Comparative cytogenetic and histologic studies on early malignant transformation in mesothelial tumors of the ovary. Hum Genet 1977, 35:281-297.

5. Crickard K, Marinello MJ, Crickard U, Satchidanand SK, Yoonessi M, Caglar H: Borderline malignant serous tumors of the ovary maintained on extracellular matrix: evidence for clonal evolution and invasive potential. Cancer Genet Cytogenet 1986, 23:135-143.

6. Yang-Feng TL, Li SB, Leung WY, Carcangiu ML, Schwartz PE: Trisomy 12 and K-ras-2 amplification in human ovarian tumors. Int J Cancer 1991, 48:678-681.

7. Jenkins RB, Bartelt D Jr, Stalboerger P, Persons D, Dahl RJ, Podratz K, Keeney G, Hartmann L: Cytogenetic studies of epithelial ovarian carcinoma. Cancer Genet Cytogenet 1993, 71:76-86.

8. Thompson FH, Liu Y, Emerson J, Weinstein R, Makar R, Trent JM, Taetle R, Alberts DS: Simple numeric abnormalities as primary karyotype changes in ovarian carcinoma. Genes Chromosomes Cancer 1994, 10:262-266.

9. Pejovic T, losif CS, Mitelman F, Heim S: Karyotypic characteristics of borderline malignant tumors of the ovary: trisomy 12 , trisomy 7 , and $r$ (1) as nonrandom features. Cancer Genet Cytogenet 1996, 92:95-98.

10. Tharapel SA, Qumsiyeh MB, Photopulos G: Numerical chromosome abnormalities associated with early clinical stages of gynecologic tumors. Cancer Genet Cytogenet 1991, 55:89-96.

11. Deger RB, Faruqi SA, Noumoff JS: Karyotypic analysis of 32 malignant epithelial ovarian tumors. Cancer Genet Cytogenet 1997, 96:166-173.

12. Wolf NG, bdul-Karim FW, Farver C, Schrock E, du MS, Schwartz S: Analysis of ovarian borderline tumors using comparative genomic hybridization and fluorescence in situ hybridization. Genes Chromosomes Cancer 1999, 25:307-315.

13. Blegen $H$, Einhorn $N$, Sjovall K, Roschke A, Ghadimi BM, McShane LM, Nilsson B, Shah K, Ried T, Auer G: Prognostic significance of cell cycle proteins and genomic instability in borderline, early and advanced stage ovarian carcinomas. Int J Gynecol Cancer 2000, 10:477-487.
14. Hauptmann S, Denkert C, Koch I, Petersen S, Schluns K, Reles A, Dietel M, Petersen I: Genetic alterations in epithelial ovarian tumors analyzed by comparative genomic hybridization. Hum Pathol 2002, 33:632-641.

15. Hu J, Khanna V, Jones MM, Surti U: Genomic imbalances in ovarian borderline serous and mucinous tumors. Cancer Genet Cytogenet 2002, 139:18-23.

16. Staebler A, Heselmeyer-Haddad K, Bell K, Riopel M, Perlman E, Ried T, Kurman RJ: Micropapillary serous carcinoma of the ovary has distinct patterns of chromosomal imbalances by comparative genomic hybridization compared with atypical proliferative serous tumors and serous carcinomas. Hum Pathol 2002, 33:47-59.

17. Helou K, Padilla-Nash H, Wangsa D, Karlsson E, Osterberg L, Karlsson P, Ried T, Knutsen T: Comparative genome hybridization reveals specific genomic imbalances during the genesis from benign through borderline to malignant ovarian tumors. Cancer Genet Cytogenet 2006, 170:1-8.

18. Micci F, Weimer J, Haugom L, Skotheim Rl, Grunewald R, Abeler VM, Silins I, Lothe RA, Trope CG, Arnold N, Heim : Reverse painting of microdissected chromosome 19 markers in ovarian carcinoma identifies a complex rearrangement map. Genes Chromosomes Cancer 2009, 48:184-193.

19. Mandahl N: Methods in solid tumors. Human Cytogenetics - a practical approach, vol II, Malignancy and acquired abnormalities Oxford: IRL PressRooney DE, Czepulkovski BH 1992, 155-187.

20. ISCN: An International System for Human Cytogenetic Nomenclature Basel: Karger S 2005

21. Sambrook J, Fritsch EF, Maniatis T: Molecular Cloning: A Laboratory Manual Cold Spring Harbor: Cold Spring Harbor Laboratory Press 2009.

22. Kearny L, Hammomd DW: Molecular Cytogenetic Technologies. Human Cytogenetics - malignancy and acquired abnormalities Oxford: Oxford University PressRooney DE , 3 2009, 129-163.

23. Brandal P, Bjerkehagen $B$, Heim S: Molecular cytogenetic characterization of tenosynovial giant cell tumors. Neoplasia 2004, 6:578-583.

24. Kallioniemi A, Kallioniemi OP, Sudar D, Rutovitz D, Gray JW, Waldman F, Pinkel D: Comparative genomic hybridization for molecular cytogenetic analysis of solid tumors. Science 1992, 258:818-821.

25. Micci F, Teixeira MR, Haugom L, Kristensen G, Abeler VM, Heim S: Genomic aberrations in carcinomas of the uterine corpus. Genes Chromosomes Cancer 2004, 40:229-246.

26. Kirchhoff M, Gerdes T, Rose H, Maahr J, Ottesen AM, Lundsteen C: Detection of chromosomal gains and losses in comparative genomic hybridization analysis based on standard reference intervals. Cytometry 1998, 31:163-173.

27. Kirchhoff M, Rose H, Petersen BL, Maahr J, Gerdes T, Lundsteen C, Bryndorf T, Kryger-Baggesen N, Christensen L, Engelholm SA, Philip J: Comparative genomic hybridization reveals a recurrent pattern of chromosomal aberrations in severe dysplasia/carcinoma in situ of the cervix and in advanced-stage cervical carcinoma. Genes Chromosomes Cancer 1999, 24:144-150.

28. Ribeiro FR, Diep CB, Jeronimo C, Henrique R, Lopes C, Eknaes M, Lingjaerde OC, Lothe RA, Teixeira MR: Statistical dissection of genetic pathways involved in prostate carcinogenesis. Genes Chromosomes Cancer 2006, 45:154-163.

29. Boland CR, Thibodeau SN, Hamilton SR, Sidransky D, Eshleman JR, Burt RW, Meltzer SJ, Rodriguez-Bigas MA, Fodde R, Ranzani GN, Srivastava S: A National Cancer Institute Workshop on Microsatellite Instability for cancer detection and familial predisposition: development of international criteria for the determination of microsatellite instability in colorectal cancer. Cancer Res 1998, 58:5248-5257.

30. Wu Q, Lothe RA, Ahlquist T, Silins I, Trope CG, Micci F, Nesland JM, Suo Z, Lind GE: DNA methylation profiling of ovarian carcinomas and their in vitro models identifies HOXA9, HOXB5, SCGB3A1, and CRABP1 as novel targets. Mol Cancer 2007, 6:45.

31. Tangir J, Loughridge NS, Berkowitz RS, Muto MG, Bell DA, Welch WR, Mok SC: Frequent microsatellite instability in epithelial borderline ovarian tumors. Cancer Res 1996, 56:2501-2505.

32. Shih YC, Kerr J, Hurst TG, Khoo SK, Ward BG, Chenevix-Trench G: No evidence for microsatellite instability from allelotype analysis of benign and low malignant potential ovarian neoplasms. Gynecol Oncol 1998, 69:210-213. 
33. Haas CJ, Diebold J, Hirschmann A, Rohrbach H, Schmid S, Lohrs U: Microsatellite analysis in serous tumors of the ovary. Int I Gynecol Pathol 1999, 18:158-162.

34. Gras E, Catasus L, Arguelles R, Moreno-Bueno G, Palacios J, Gamallo C, Matias-Guiu X, Prat J: Microsatellite instability, MLH-1 promoter hypermethylation, and frameshift mutations at coding mononucleotide repeat microsatellites in ovarian tumors. Cancer 2001, 92:2829-2836.

35. Sanz Casla MT, Vidaurreta LM, Almansa dL I, Tresserra F, Lopez ML, Maestro ML, Dexeus S: Role of microsatellite instability in borderline ovarian tumors. Anticancer Res 2003, 23:5139-5141.

36. Wolf NG, Farver C, bdul-Karim FW, Schwartz S: Analysis of microsatellite instability and $\mathrm{X}$-inactivation in ovarian borderline tumors lacking numerical abnormalities by comparative genomic hybridization. Cancer Genet Cytogenet 2003, 145:133-138

37. Micci F, Heim S: Tumors of the Female Genital Organs. Cancer Cytogeentics - Chromosomal and Molecular Genetic Aberrations of Tumor Cells New Jersey: Wiley-BlackwellHeim S, Mitelman F , 3 2009, 519-575.

38. Osterberg L, Akeson M, Levan K, Partheen K, Zetterqvist BM, Brannstrom M, Horvath G: Genetic alterations of serous borderline tumors of the ovary compared to stage I serous ovarian carcinomas. Cancer Genet Cytogenet 2006, 167:103-108

39. Godwin AK, Vanderveer L, Schultz DC, Lynch HT, Altomare DA, Buetow KH, Daly M, Getts LA, Masny A, Rosenblum N: A common region of deletion on chromosome $17 q$ in both sporadic and familial epithelial ovarian tumors distal to BRCA1. Am J Hum Genet 1994, 55:666-677.

40. Phillips NJ, Zeigler MR, Deaven LL: A cDNA from the ovarian cancer critical region of deletion on chromosome 17p13.3. Cancer Lett 1996, 102:85-90.

41. Saretzki G, Hoffmann U, Rohlke P, Psille R, Gaigal T, Keller G, Hofler H, Loning T, Petersen I, Dietel M: Identification of allelic losses in benign, borderline, and invasive epithelial ovarian tumors and correlation with clinical outcome. Cancer 1997, 80:1241-1249.

42. Schultz DC, Vanderveer L, Berman DB, Hamilton TC, Wong AJ, Godwin AK: Identification of two candidate tumor suppressor genes on chromosome 17p13.3. Cancer Res 1996, 56:1997-2002.

43. Schuijer M, Berns EM: TP53 and ovarian cancer. Hum Mutat 2003, 21:285-291.

44. Shelling AN, Cooke IE, Ganesan TS: The genetic analysis of ovarian cancer. Br J Cancer 1995, 72:521-527.

45. Skilling JS, Sood A, Niemann T, Lager DJ, Buller RE: An abundance of p53 null mutations in ovarian carcinoma. Oncogene 1996, 13:117-123.

46. Skomedal H, Kristensen GB, Abeler VM, Borresen-Dale AL, Trope C, Holm R: TP53 protein accumulation and gene mutation in relation to overexpression of MDM2 protein in ovarian borderline tumours and stage I carcinomas. J Pathol 1997, 181:158-165.

47. Caduff RF, Svoboda-Newman SM, Ferguson AW, Johnston CM, Frank TS: Comparison of mutations of Ki-RAS and p53 immunoreactivity in borderline and malignant epithelial ovarian tumors. Am J Surg Pathol 1999, 23:323-328.

48. Schuyer M, Henzen-Logmans SC, Burg van der ME, Fieret JH, Derksen C, Look MP, Meijer-van Gelder ME, Klijn JG, Foekens JA, Berns EM: Genetic alterations in ovarian borderline tumours and ovarian carcinomas. Eur $J$ Obstet Gynecol Reprod Biol 1999, 82:147-150.

49. Cornelis RS, Neuhausen SL, Johansson O, Arason A, Kelsell D, Ponder BA, Tonin P, Hamann U, Lindblom A, Lalle P, et al: High allele loss rates at 17q12-q21 in breast and ovarian tumors from BRCAl-linked families. The Breast Cancer Linkage Consortium. Genes Chromosomes Cancer 1995, 13:203-210.

50. Israeli O, Gotlieb WH, Friedman E, Goldman B, Ben-Baruch G, viramGoldring A, Rienstein S: Familial vs sporadic ovarian tumors: characteristic genomic alterations analyzed by CGH. Gynecol Oncol 2003, 90:629-636.

doi:10.1186/1479-5876-8-21

Cite this article as: Micci et al:: Genomic aberrations in borderline ovarian tumors. Journal of Translational Medicine 2010 8:21.

\section{Submit your next manuscript to BioMed Central and take full advantage of:}

- Convenient online submission

- Thorough peer review

- No space constraints or color figure charges

- Immediate publication on acceptance

- Inclusion in PubMed, CAS, Scopus and Google Scholar

- Research which is freely available for redistribution

Submit your manuscript at www.biomedcentral.com/submit
C Biomed Central 